This is a self-archived version of an original article. This version may differ from the original in pagination and typographic details.

Author(s): Lahti, Malgorzata

Title: Diversity and Social Interaction at Work

Year: 2020

Version: Accepted version (Final draft)

Copyright: (c) 2020 Taylor \& Francis

Rights: In Copyright

Rights url: http://rightsstatements.org/page/lnC/1.0/?language=en

Please cite the original version:

Lahti, M. (2020). Diversity and Social Interaction at Work. In L. Mikkola, \& M. Valo (Eds.), Workplace Communication (pp. 110-122). Routledge. https://doi.org/10.4324/97804291968819 


\title{
$9 \quad$ Diversity and Social Interaction at Work
}

\author{
Malgorzata Lahti 0000-0002-0396-4695
}

Today's workplaces are characterized by interactions among people with diverse backgrounds. These interactions may occur face-to-face or in technology-mediated settings; as interpersonal exchanges between co-workers, supervisors, and subordinates or between business partners and clients; in small groups and teams or as one-off encounters with customers. The persons engaged in these interactions jointly strive for the shared goals of their organization though they may come from different countries, speak different first languages, or identify with different ethnic, gender, or age groups. This chapter explores the role of diversity in different workplace contexts and situations. First, we unpack the concept by presenting the objective and subjective approaches to workplace diversity. The objective approach considers nationality, ethnicity, gender, or age-related differences as biologically determined facts. Subjective diversity, on the other hand, focuses on people's individual and shared experiences and their practices of integrating and standing out within their work lives. Following a discussion of the challenges of the objective approach, the chapter offers a framework for exploring workplace diversity as a subjective social construct. The framework is based on concepts of identification and othering, the complexities of disadvantage, language competences, and the construction of a shared culture.

\section{Introduction}

Social environments today are becoming increasingly pluralistic, and the workplace is no exception. Mobility and cultural and linguistic exchanges are certainly not unique to the times we live in; they have always been a staple feature of the human experience. However, these days, the flows of people, technologies, money, images, and ideas that undergird globalization have not only intensified but also become multidirectional, multidimensional, and populated by multiple actors. Developments in communication technologies have enabled a new level of global interconnectedness. These transformations are also reflected in the current reorganization of the global economy, characterized by internationalization and offshoring of activities as well as the expansion of service and knowledge-intensive work sectors. As a result, contemporary working life has come to build on the interplay of individuality and interaction, with more specialized career choices, unique expertise, non-traditional career paths and employment patterns, on the one hand, and a considerable emphasis on language and interaction, mobility, networking, and teamwork (mediated by technology among dispersed teams), on the other.

Against this backdrop, working with people whose backgrounds are different from one's own has become the rule rather than the exception for many. In organizations, people who have grown up in different countries, speak different first languages, or identify with different ethnic, gender, or age groups engage in shared activity and are aligned toward a shared future together. Such interactions occur either face-to-face or with the help of communication technologies. They may occur in the context of interpersonal relationships between peers, supervisors, and subordinates; or between business partners and clients; in small groups and teams; or in one- 
off encounters with customers. In all of these workplace contexts and situations, diversity may become potentially relevant. Organizational members may, for instance, face discriminatory acts based on the ethnic, gender, age-or based category they identify with. National or ethnic identities may be used to claim expertise, shirk responsibility, or explain one's own or someone else's behavior. Lack of competence in the dominant language at the workplace may affect organizational members' participation in meetings or informal socialization with colleagues. The aim of this chapter is to explore the role of diversity in different workplace contexts and situations. We start by unpacking the concept of diversity itself, and move on to offer a framework for exploring workplace diversity as a subjective social construct.

\section{What Is Workplace Diversity?}

The concept of "diversity" carries with it some baggage that needs to be unpacked before we move on. Diversity has been construed variously in research literature, depending on the authors' area of research, interests, and biases. The distinction between objective and subjective diversity (e.g., Mannix \& Neale 2005) effectively captures the fundamental differences between the various views.

Objective diversity refers to external markers of difference represented in social category labels. Nationality, ethnicity, gender, or age-related differences are considered biologically determined facts. On the other hand, subjective diversity focuses on people's individual and shared experiences of being different and the practices through which differences among organizational members are locally produced. The latter understanding resonates with the constitutive view of interaction promoted in this volume. We see interaction as the construction and negotiation of meanings between two or a few persons (Braithwaite, Schrodt, \& Carr 2015, 6). In negotiating meaning, interactants implicitly or explicitly develop a new, shared understanding about the nature of persons, physical entities, or situations by exchanging with each other their interpretations of the object at hand and by helping the other modify their respective understanding to approximate their own. It is through producing and negotiating meanings that we define our social milieu, our sense of self, and our relationship to others. It is in and through interaction that the relevance and meanings of different identities are created.

\section{Objective Diversity}

The objective view of workplace diversity has been predominant in both theory and practice. As mentioned, this approach considers diversity to be represented in organizational members' heterogeneous demographic dimensions or social categories. These dimensions can encompass 
Lahti, M. (2020). Diversity and social interaction at work. In L. Mikkola \& M. Valo (Eds.), Workplace communication. New York: Routledge.

anything from nationality, ethnicity, language, through age, gender, and sexuality, to educational background and social class. These social categories are seen as unique entities associated with values, cognitive patterns, and communicative styles that form the essence of the people belonging to the category. Simply put, group membership is considered a given (see Piller 2012). Under this view, a workplace is diverse if the staff consists of holders of different passports, speakers of different first languages, or members of different age groups.

As an objective fact, diversity has typically been examined in workplace literature as either a resource or a challenge to organizational functioning and outcomes (Lahti 2015a; Lahti \& Valo 2017). The purported differences in interpretations, knowledge, and skills of diverse employees have been related to better decision-making, innovation, and learning. At the same time, diversity has also been associated with misunderstandings, formation of sub-groups, and conflict and discrimination of minority employees. Because of this apparent binary effect, organizational diversity has come to be viewed as a double-edged sword.

On the level of practice, the influence of diversity on employee, and therefore organizational, performance, is examined in the managerial approach of diversity management. Diversity management was developed in the United States in the late 1980s and gradually became a globally acknowledged organizational strategy for dealing with employee diversity (Omanovic 2009). Diversity management typically encompasses policy formulations and practices, such as training, mentoring, and career development (Prasad, Prasad, \& Mir 2010), that managers and leaders can utilize to effectively guide and supervise their diverse subordinates. Diversity management draws on the economic argument that differences inherent to different social categories represented in the organization can be harnessed to improve workplace productivity (Lorbiecki \& Jack 2000). Within diversity management, it is managers and leaders who wield the diversity sword as they are responsible for maximizing the benefits and minimizing the threats associated with a diverse staff.

Such strategic, polarized, and mechanistic arguments about diversity have provoked criticism. In fact, the whole idea of explaining diversity as naturally and in a common-sense way associated with the social categories ascribed to persons has come under attack in recent research literature. To learn more about the critique, it will be useful to examine some of the problematic assumptions and consequences of the seemingly innocuous concept of diversity, discussed by the intercultural communication scholar Fred Dervin (2017). These are essentialism, othering, anthropomorphy, excuse/alibi, and marketing.

The traditional understanding of diversity carries essentialist assumptions. Essentialism (Holliday 2011, 4) presents different categories such as nationality, ethnicity, age, or gender as 
pre-existing and entirely defining people's behavior. We rely on essentialism when we talk about "Finnish business communication," "Chinese cultural values," "female leadership style," or “older workers' fear of communication technologies." Seen in essentialist terms, differences can be used to construct an idealized image of one's own group and, subsequently, to develop and apply a deficient image of "them" or the "other" through the process of othering (ibid., 6970). In simple terms, othering consists in framing the other as fundamentally different, strange, exotic, or less sophisticated. Othering is further linked to anthropomorphy (Dervin 2017), whereby diversity assumes an identity or agency of its own, eliminating subjectivity from the people it is used to describe. An examination of the diversity management concept shows how the label of diversity is used to objectify different employee groups and portray them as a potential problem to organizational functioning, which needs to be handled and controlled by managers - who themselves, apparently, are not diverse (Kirby \& Harter 2003).

As Dervin (2017) observes, it is typical for mainstream applications of diversity to present the other as strange, exotic, and deprived of agency ("driven by their culture"), while appreciating and enjoying one's own individuality, independence, and freedom. Just like nationality and ethnicity, chronological age and gender serve as pervasive explanations for the behavior of others. This may manifest in workplace ageism and sexism that pivot on a prejudiced belief about people's' professional competence being determined by their age or gender. Diversity may become an easy explanation - an excuse or alibi - for why we treat the other in a prejudiced way ("it's his culture" or "she's simply too young/old for the job"). There is ample evidence that organizational decision-makers' sexist attitudes may lead to gender-biased decisions and practices that negatively affect women's career opportunities and organizational well-being (Stamarski \& Son Hing 2015). It has also been observed that older employees may be perceived as inadvertently growing incompetent and face harsher repercussions for performance failures (Rupp, Vodanovich, \& Crede 2006).

As discussed earlier, diversity also has a positive note to it. It has been linked to spurring creativity and innovation. Embracing diversity is widely taken to be a sign of open-mindedness and tolerance, and has, therefore been used in marketing. In fact, Prasad et al. (2010) have argued that diversity management programs and initiatives have become so fashionable that it may prove too expensive for an organization not to adopt to them. Sadly, the ongoing replication of trendy though uniform and cosmetic managerial techniques serves to mask the real diversity dynamics and inequalities in workplaces (ibid.).

Apart from adopting diversity management strategies, organizations may brand themselves as inclusive and progressive by intentionally hiring persons occupying non-mainstream social 
Lahti, M. (2020). Diversity and social interaction at work. In L. Mikkola \& M. Valo (Eds.), Workplace communication. New York: Routledge.

categories - a phenomenon known as tokenism (Kanter 2003). Tokenism, of course, can have serious repercussions for one's organizational experiences. Staking a claim to organizational diversity by favoring empty social categories, such as nationality or gender, undermines people's true professional expertise and individual life experience. For instance, female sports journalists have recounted the stress of having to carefully manage their professional and gender identities to prove that they actually deserve their jobs in the predominantly male newsroom (Hardin \& Whiteside 2009).

\section{Subjective Diversity}

Critically discussing the assumptions associated with diversity can help us understand that diversity is itself a social construct, though people tend to take it for granted and see it as natural and legitimate (Dervin 2017). The subjective approach to workplace diversity considers people's subjective and intersubjective constructions of differences in working life. It treats different identities not as factual categories that exist outside of the people but as something that people talk into being, in interaction. This view acknowledges that people's constructions of difference may be informed by popular stereotypical representations of groups upheld in public discourses, for instance, in the media or in politics.

Piller (2012) encourages us to scrutinize the nature of group memberships that we typically see as underpinning diversity. Nationality, ethnicity, religion, gender, or age-based collectives are too large to be real groups in the sense that one could never meet, interact with, or even learn of, all the other group members (ibid.). Therefore, it is more fitting to approach these collectives as imagined communities (Anderson 2006), whereby persons picture themselves, and are pictured by others, as group members (Piller 2012). Categories such as nation, ethnicity, gender, or age are not natural or neutral, and they do not pre-exist and shape people by imbuing them with some essential qualities. Rather, they are produced in interaction and are, thus, social or discursive constructs. We imagine the characteristics associated with specific groups, and we claim them for ourselves or attribute them to others; we negotiate their relevance and meaning through interaction. That is why, instead of predicting how people inhabiting different social categories behave, we should pay attention to who makes different identities "relevant to whom in which context for which purposes" (Piller 2011, 13). Attending to diversity (and its management) as the result of such discursive constructions may yield profound insights for practice (Prasad et al. 2010). 


\section{Tools for Understanding Subjective Diversity at Work}

\section{Identification and Othering}

When seen from an analytical perspective, identification can be a process. It encourages us to abandon static descriptions of social categories and examine identities as contingent, multiple, complex, and ever changing. In workplace interactions, people may want to claim a specific identity for a variety of reasons - for instance, to position themselves as experts, to avoid responsibility, or to please another. Identities also have a relational component. In other words, they are not only based on how we see ourselves or what we want to reveal about ourselves but also on how others see us on the basis of their background knowledge or their interpretations of the cues we give away. We are never fully in control of the identification processes, and we may be othered even if we do not perceive ourselves as different.

Processes of identification and othering are in constant flux, and they may inform workplace interaction in various ways. For instance, a group of highly-skilled female Russian immigrants in Finland working in knowledge-intensive jobs did not perceive "Russianness" to be a permanent feature of their workplace interactions (Lahti 2013). Being Russian occasionally emerged in communication and meant different things to different persons depending on the context. Some of the women saw Russianness as informing their professionalism and often surfacing in the way they accomplished tasks or communicated with others at work. They wished their different background would receive more attention from their colleagues and supervisors. Others perceived their Russian background as irrelevant and reported being only occasionally reminded of it when colleagues asked their opinion on political developments in Russia, or when their language skills were used in sporadic translation tasks. Persons interacting with strangers on a daily basis often found themselves othered and, at times, confronted with threatening stigmatizing ascriptions, as their identities could be inferred from their names or from the way they spoke Finnish.

Seeing the other as belonging to a different category may prompt exclusion from social interaction at work. For instance, people may combine the stereotypes of age and sexuality to explain whom they socialize with in the office (Dixon 2012). Older coworkers may be seen as different from the norm because they may be perceived as devoid of a sexual identity and therefore unsuitable for inclusion in workplace chit-chat (ibid.).

Stereotypical ideas about others based on our perceptions of their social category may also serve as an excuse or justification for discrimination. This point is illustrated in observations from a Saudi subsidiary of a Danish corporation (Lauring 2011). In that workplace, Danish 
Lahti, M. (2020). Diversity and social interaction at work. In L. Mikkola \& M. Valo (Eds.), Workplace communication. New York: Routledge.

managers were found to use stereotypical images about the nationality of their subordinates to justify the way power and privileges were allocated to different employee groups. The organization followed an ethnically segregated hierarchy where "one had to be European to be a manager and Egyptian to be a supervisor" (ibid., 243). Indian employees, regarded as possessing the least cognitive ability, were relegated to the lowest positions in sales and production (ibid.).

\section{Complexities of Disadvantage}

Although imagined, cultural and social identities are by no means any less real; being imagined as members of less prestigious groups may have very tangible consequences for the working life of individuals. While power inequalities, prejudice, and discrimination have been given ample attention in workplace literature, these discussions have mostly focused on members of specific social categories who experience mistreatment because of their natural differences (Lahti 2015a; Lahti \& Valo 2017). Intersectionality is an alternative approach that offers a more nuanced understanding of oppression. It views oppression as fluid and occurring at the crossroads of interpersonal acts of mistreatment and social structures and ideologies. Taking as a point of departure the multiple and simultaneous threats faced by women of color, intersectionality emphasizes that social identities cannot be studied in isolation since they are interlocking, mutually constituted, and intertwined with structures of power (Dill \& Kohlman 2012).

Intersectionality enables us to develop more thorough, nuanced, and complex analyses of the lived experiences of non-mainstream organizational members and organizational practices that produce diversity. It appears, for instance, that ethnic minority women in the United Kingdom (Kamenou \& Fearfull 2006) and Hispanic and African American women in the United States (Richardson \& Taylor 2009) may face threatening situations at work that cannot be explained by gender alone. Similarly, young women may have to develop strategies to confront the combined effects of ageism and sexism in their professional lives (Worth 2016). These strategies may include framing one's experiences of mistreatment as inherent to early career stages or as "temporary exploitation" or adjusting one's communication style and dress to appear older and less "girlie" (ibid., 1307-1308). We also know that age and ethnicity may have a joint effect on a person's career development. For instance, older African American professionals are more susceptible to downward mobility than any other social group in the USA, which cannot be accounted for by traditional explanations such as labor market characteristics (Wilson \& Roscigno 2018). 
Experiences of oppression cannot exist without experiences of privilege (Collins 1990, cited in Dill \& Kohlman 2012). This is certainly true in the case of workplace language ideologies and practices that exclude and privilege different employee groups in different ways. For instance, in an English-speaking multinational organization located in Denmark, the employees occupying the lowest rung of the organizational hierarchy, such as cleaners, were excluded from most organizational communication because of their low proficiency in English, which was the official organizational language (Lønsmann 2014). At the same time, high-ranking international managers in the same organization found themselves hitting a glass ceiling as their poor knowledge of Danish became an obstacle to further career development (ibid.).

\section{Language Competences}

Interactions between persons with different national or ethnic affiliations often take place in a language that is not the first or strongest language for at least one of the parties involved.

Competence in the language(s) of interaction has nevertheless been given little attention in traditional intercultural and organizational communication research. Language has typically been treated as a neutral channel for an underlying national culture. Emergent problems in interaction have typically been diagnosed as cultural problems, although language issues could well be at the root (Piller 2012). Very recently, research has moved toward treating language as a social tool. These studies show that by incorporating the language competence perspective, we can uncover completely new facets about workplace interactions and, hopefully, design more fitting interventions, should there be a need.

Low proficiency in the language of the workplace may hinder successful job performance. For instance, immigrants in knowledge-intensive jobs in Finland shared that low proficiency in Finnish prevented them from actively participating in meetings and trainings, processing organizational documents, or acquiring vital information on company policies and practices (Välipakka, Zeng, Lahti, \& Croucher 2016). They complained that their professional agency was undermined as they had to constantly rely on others for interpretation. We also know that low competence in the language of the workplace may be misinterpreted by others as lack of professional expertise. For instance, university students in English-taught courses may mistake their lecturer's poor English skills for inadequate knowledge of the subject matter (Jensen, Denver, Mees, \& Werther 2013).

Introducing English (or any other language) as a company's lingua franca may create many challenges for relational development and knowledge sharing. It has been observed, for example, that many organizational members feel anxious when forced to communicate in 
Lahti, M. (2020). Diversity and social interaction at work. In L. Mikkola \& M. Valo (Eds.), Workplace communication. New York: Routledge.

English (Tange \& Lauring 2009). This can lead to the emergence of alternative interaction patterns, such as thin communication, where persons limit their interactions with others to unavoidable work-related matters, and language clustering, where speakers of the same first language form groups in which to socialize (ibid.). Alleviating such communication problems calls for the building of a workplace culture where communicative ability is valued over linguistic correctness.

\section{Construction of a Shared Culture}

The true challenge of relating to and working with others is not making accurate predictions about how people supposedly belonging to large collectives (e.g., nationality, ethnicity, gender, age) differ. We can, however, redeem the task of cultural description by shifting our attention to a different type of group - a real group (also known as a "small group" to many scholars interested in organizations). This type of group is composed of a few persons who interact with one another on a regular basis. In the world of work, small groups can come in the shape of companies, work groups, teams, and relationships. Through frequent interactions with our colleagues, whether face-to-face or in technology-mediated ways, we develop mutual understandings, interpretations, practices, and even language - in other words - a shared culture.

From the perspective of diversity, it is worthwhile examining how persons' memberships in different social categories are systematically treated in the shared culture of the workplace. Are constructions of diverse identities something everyone agrees with? Does everyone have an equal say in how we define ourselves as a group and negotiate ways of working together? To offer an example, members of an international project team unanimously used the concept of cultural diversity to present their project in a highly positive light - as more innovative and complex than the more traditional national-level collaboration (Barinaga 2007). On the other hand, cultural diversity may also act as an explanation for challenges in teamwork, such as interpersonal communication problems (Dameron \& Joffre 2007).

The focus on a shared workplace culture encourages us to appreciate all the things we have in common as persons and professionals in our own right. Some studies of diverse organizations have, in fact, found that members' different social categories do not need to be made relevant at all. For instance, Catholics and Protestants working together in Northern Irish organizations did not perceive their backgrounds as salient because they all felt united by their professional and organizational identities (Dickson, Hargie, \& Wilson 2008). A study investigating cultural knowledge sharing in a team whose members were located in Finland and Russia, spoke 
Finnish or Russian respectively as their first language, and mostly relied on communication technologies for interaction found that while cultural expertise related to either Finland or Russia was shared, it was not tied to team members' national backgrounds (Lahti 2015b). One did not need to be Russian to be an expert on Russian matters or vice versa. The team had developed a culture where everyone had the right to be a cultural expert in relation to both national contexts.

\section{Practical Implications}

We should recognize the dangers of working with simplistic essentialist ideas about others, often materialized in the form of cultural descriptions of different social categories. Such representations of the other may be attractively straightforward and intuitively appealing, but they come at a high price. Having presuppositions about what people from different national, ethnic, gender, or age groups are like or what they want may be counterproductive.

It is important to note that popular diversity trainings and consultations offered to organizations tend to be based on such old-fashioned essentialist understandings of differences. Such trainings should be approached with caution as they may help reinforce prejudice and divisions rather than counter them or introduce any meaningful change into the workplace.

The concept of diversity has come to be associated with non-mainstream organizational members who are framed as potentially problematic, unusual, and driven by the category to which they are seen as belonging. We should critically examine the assumption that mainstream identities are somehow uniform, similar, coherent, and normal and come to appreciate the fact that we are all different (Dervin, 2017). We all have complex, dynamic, and diverse identities. Some of the aspects of our sense of self derive from our personal qualities, trajectories, and relationships, while others relate to our group memberships. At any point in time, we have different options or action plans at our disposal. Some of them are cultural, some are not. Therefore, it may be oppressive to assume that the others only have social categoryrelated scenarios in their repertoire.

Noticing or acknowledging the other's different background is generally taken to be a sign of politeness and a demonstration of an open mindset. However, such attention may come across as stifling or burdensome to your different colleague. Being asked questions like "How did you end up in this country?" or "How does it feel to be the only man in the team?" may feel nice to some people sometimes. However, it may also induce a sense of discomfort because not everyone wants to disclose information about their personal lives. Such attention may feel unwanted or annoying as workplace members want to be seen as fellow colleagues and not 
Lahti, M. (2020). Diversity and social interaction at work. In L. Mikkola \& M. Valo (Eds.), Workplace communication. New York: Routledge.

singled out as foreigners/immigrants/representatives of a specific gender or age group. The focus on superficial markers of difference (customs, festivals, traditional dishes) simplifies people's cultural identities to cardboard figures and deprives them of their personhood. In general, we should heed the observation of anthropologist Eriksen (2001) that everyone should have the right not to have a culture (or a social category, for that matter) and be seen as a person in their own right.

While culture is often offered as a convenient explanation for anything strange, surprising, or challenging in an interaction, issues of language proficiency could be at the root of the problem. We should guard against misdiagnosing language-related issues as cultural or as poor professionalism.

Instead of taking people's claims about culture as a given, we could imagine we are ethnographers and turn our attention to answering the question, "Who makes culture relevant to whom in which context for which purposes?" (Piller 2011, 13). How are different social identities or categories brought up in your everyday workplace interactions? Who does it? Why? What are they possibly trying to achieve? Is diversity introduced to present the team as modern and dynamic or to account for interpersonal conflicts? Are group memberships mentioned to support claims of expertise and professionalism, or maybe to avoid responsibility? Examining such constructions can tell us a lot about our workplace interactions and our work community.

Better still, rather than focusing on differences, we should embrace the similarities. The workplace offers myriad opportunities for us to discover and enjoy shared aspects of our identities. After all, we most likely have similar educational backgrounds and areas of expertise. Moreover, we can relate to one another through the interdependent tasks on which we collaborate and the organizational or team goals for which we aspire. The workplace offers situations, activities, and forms of work that encourage the development of close interpersonal bonds. These bonds may even develop into close intimate ties such as friendship. Getting to know the others personally offers a way of finding out about their preferences in terms of how they would like to be seen and treated in their work community, for instance, when or whether they find it acceptable to be singled out as a different other.

The privilege of working in established work groups, teams, or relationships is not available to all persons in the working life. Those occupying organizational frontlines and interacting with strangers on a daily basis (e.g., service sector workers) may face the challenge of having to negotiate their social identities every day. Tangible cues that give away one's different identity category, such as a foreign accent, skin color, gender, or age-related physical characteristics, 
may encourage othering and threatening reactions that pivot on racism, ageism, or sexism. Managing such challenging encounters is complicated by the fact that customer service interactions are imbued with a set of power relations and the requirement to display positive emotions. Those engaged in such interactions should receive extra support in dealing with and managing the emotional labor involved (see Gradney, Rupp, \& Brice 2015).

The idea of national, ethnic, gender, or age-based collectives as imagined may make these categories appear innocent and even playful. However, membership in these communities is not less real as it may have serious and concrete consequences, such as culture, gender, or agerelated discrimination. Social constructs of difference are maintained and supported by representations of groups in the media. They are also intertwined with structures and material representations of oppression. Negative representations and ideologies about groups may enter interpersonal interactions and, for instance, make someone reluctant to reveal a stigmatized identity. We should also acknowledge that structural discrimination in the form of gendered pay inequalities or limited access to jobs for young/older persons demands fundamental structural changes and cannot be alleviated simply through interpersonal communication training.

\section{What to Consider in the Workplace}

- Fixed ideas about persons belonging to a specific social category are naïve and simplistic.

- Be cautious of popular diversity trainings and consultations that offer easy-fix solutions to organizational diversity issues.

- We are all different in complex ways; different is not a label for those organizational members who occupy minority categories.

- Noticing the other's different background is not necessarily polite, and it can be experienced as an act of imposition or othering.

- While culture is a convenient explanation, there often are other better explanations, such as a person's competence in the language of interaction.

- Examine how and why people make different social identities visible in everyday workplace interactions, this can reveal quite a lot about your workplace dynamics.

- It makes more sense to embrace the similarities you share with others at work, rather than identifying differences.

- Persons working on organizational frontlines may be prone to experiencing more stereotyping, othering, and mistreatment than those working in established workplace relationships, groups, and teams.

- While national, ethnic, gender or age-based identities are imagined, they may have real consequences such as when negative representations and ideologies about groups enter interpersonal interactions or when a person's career development is affected by their age, gender, or ethnicity.

- Structural discrimination will not be alleviated through interpersonal communication training. 
Lahti, M. (2020). Diversity and social interaction at work. In L. Mikkola \& M. Valo (Eds.), Workplace communication. New York: Routledge.

\section{References}

Anderson, B. 2006. Imagined communities. Revised ed. London: Verso.

Barinaga, E. 2007. "Cultural diversity" at work: "National culture" as a discourse organizing an international project group. Human Relations 60, 315-340.

Braithwaite, D. O., Schrodt, P. \& Carr, K. 2015. Introduction: Meta-theory and theory in interpersonal communication research. In D. O. Braithwaite \& P. Schrodt (Eds) Engaging theories in interpersonal communication: Multiple perspectives. 2nd ed. Los Angeles: Sage, $1-20$.

Dameron, S. \& Joffre, O. (2007). The good and the bad: The impact of diversity management on co-operative relationships. International Journal of Human Resource Management 18, 2037-2056.

Dervin, F. 2017. The unbearable lightness of diversity-speak. In Critical interculturality: Lectures and notes. Newcastle: Cambridge Scholars Publishing, 59-68.

Dickson, D., Hargie, O. \& Wilson, N. 2008. Communication, relationships, and religious difference in the Northern Ireland workplace: A study of private and public sector organizations. Journal of Applied Communication Research 36, 128-160.

Dill, B. \& Kohlman, M. 2012. Intersectionality: A transformative paradigm in feminist theory and social justice. In S. N. Hesse-Biber (Ed.) Handbook of feminist research: Theory and praxis. Thousand Oaks, CA: Sage, 154-174.

Dixon, J. 2012. Communicating (st)ageism: Exploring stereotypes of age and sexuality in the workplace. Research on Aging 34(6), 654-669.

Eriksen, T. H. 2001. Between universalism and relativism: A critique of the UNESCO concept of culture. In J. Cowan, M.-B. Dembour \& R. Wilson (Eds.) Culture and rights: Anthropological perspectives. Cambridge: Cambridge University Press, 127-148.

Gradney, A. A., Rupp, D. \& Brice, W. N. 2015. Emotional labor threatens decent work: A proposal to eradicate emotional display rules. Journal of Organizational Behavior 36, 770 785.

Hardin, M. \& Whiteside, E. 2009. Token responses to gendered newsrooms: Factors in the career-related decisions of female newspaper sports journalists. Journalism 10(5), 627-646.

Holliday, A. 2011. Intercultural communication and ideology. Thousand Oaks, CA: Sage.

Jensen, C., Denver, L., Mees, I. M., \& Werther, C. 2013. Students' attitudes to lecturers' English in English-medium higher education in Denmark. Nordic Journal of English Studies, 13(1), 87-112.

Kamenou, N. \& Fearfull, A. 2006. Ethnic minority women: A lost voice in HRM. Human Resource Management Journal 16, 154-172.

Kanter, R. 2003. Men and women of the corporation. In R. J. Ely, E. G. Foldy \& M. A. Scully (Eds.) Reader in gender, work, and organization. Malden, MA: Blackwell, 34-48. 
Kirby, E. L. \& Harter, L. M. 2003. Speaking the language of the bottom-line: The metaphor of "managing diversity." Journal of Business Communication 40(1), 28-49.

Lahti, M. 2015a. Communicating interculturality in the workplace. Doctoral dissertation. Jyväskylä Studies in Humanities 262. University of Jyväskylä, Jyväskylä, Finland. Retrieved from https://jyx.jyu.fi/dspace/handle/123456789/47257

Lahti, M. 2015b. Sharing cultural knowledge at work: A study of chat interactions of an internationally dispersed team. Language and Intercultural Communication 15, 513-532.

Lahti, M. 2013. Cultural identity in everyday interactions at work: Highly-skilled female Russian professionals in Finland. Nordic Journal of Working Life Studies 3, 21-43.

Lahti, M. \& Valo, M. 2017. Intercultural workplace communication. In Oxford research encyclopedia of communication. Oxford: Oxford University Press. Retrieved from http://communication.oxfordre.com/view/10.1093/acrefore/9780190228613.001.0001/acr efore-9780190228613-e-404.

Lauring, J. 2011. Intercultural organizational communication: The social organizing of interaction in international encounters. Journal of Business Communication 48, 231-255.

Lønsmann, D. 2014. Linguistic diversity in the international workplace: Language ideologies and processes of exclusion. Multilingua 33(1-2), 89-116.

Lorbiecki, A. \& Jack, G. 2000. Critical turns in the evolution of diversity management. British Journal of Management 11, S17-S31.

Mannix, E. \& Neale, M. 2005. What differences make a difference? The promise and reality of diverse teams in organizations. Psychological Science in the Public Interest 6, 31-55.

Omanovic, V. 2009. Diversity and its management as a dialectical process: Encountering Sweden and the US. Scandinavian Journal of Management 25, 352-362.

Piller, I. 2011. Intercultural communication: A critical introduction. Edinburgh: Edinburgh University Press.

Piller, I. 2012. Intercultural communication: An overview. In C. B. Paulston, S. F. Kiesling \& E. S. Rangel (Eds.) The handbook of intercultural discourse and communication. Malden, MA: Wiley Blackwell, 3-18.

Prasad, A., Prasad, P. \& Mir, R. 2010. "One mirror in another": Managing diversity and the discourse of fashion. Human Relations 64(5), 703-724.

Richardson, B. K. \& Taylor, J. 2009. Sexual harassment at the intersection of race and gender: A theoretical model of the sexual harassment experiences of women of color. Western Journal of Communication 73(3), 248-272.

Rupp, D. E., Vodanovich, S. J. \& Crede, M. 2006. Age bias in the workplace: The impact of ageism and causal attributions. Journal of Applied Social Psychology 36(6), 1337-1364.

Stamarski, C. S. \& Son Hing, L. S. 2015. Gender inequalities in the workplace: The effects of organizational structures, processes, practices, and decision makers' sexism. Frontiers in Psychology 6, 1400. 
Lahti, M. (2020). Diversity and social interaction at work. In L. Mikkola \& M. Valo (Eds.), Workplace communication. New York: Routledge.

Tange, H. \& Lauring, J. 2009. Language management and social interaction within the multilingual workplace. Journal of Communication Management 13(3), 218-232.

Välipakka, H., Zeng, C., Lahti, M. \& Croucher, S. 2016. Experiencing cultural contact at work. An exploration of immigrants' perceptions of work in Finland. In S. Shenoy-Packer \& E. Gabor (Eds.) Immigrant workers and meanings of work: Communicating life and career transitions. New York: Peter Lang, 21-32.

Wilson, G. \& Roscigno, V. J. 2018. Race, ageism and the slide from privileged occupations. Social Science Research 69, 52-64.

Worth, N. 2016. Who we are at work: Millennial women, everyday inequalities and insecure work. Gender, Place \& Culture 23(9), 1302-1314. 